\title{
Lysosomal Activity and its Control in Encysting Hartmannella castellanii
}

\author{
By A. J. GRIFFITHS AND S. MAUREEN BOWEN \\ Department of Microbiology, University College \\ of South Wales and Monmouthshire, Cardiff, CF I 3 NR
}

(Accepted for publication 28 August 1969)

\begin{abstract}
SUMMARY
A latent, non-specific phosphatase of Hartmannella castellanii with an optimum $\mathrm{pH}$ of $4^{\circ} \mathrm{O}$ has been investigated. The latency could be released in cell-free homogenates by treatment with Triton $\times 100$, freezing and thawing, refrigeration or carbon tetrachloride. It seems likely that this enzyme is attached to a sub-cellular organelle as it was largely sedimentable when homogenates were prepared in media containing sucrose.

During encystation of the amoebae under controlled conditions there was no appreciable change in the levels of total phosphatase activity measured in frozen-thawed extracts, but there were quite large increases in free activities of fresh, unfrozen preparations. Inhibitors and promoters of encystation were also found to affect the levels of phosphatase activity in the amoebae but did not affect its sedimentability which persisted throughout the initial degradative phase of encystment.

Incubation of homogenates of Hartmannella decreased the latency of the acid phosphatase but this activation could be modified by substances which are known to affect the encystation responses of the amoebae.

It is concluded that the degradative phase of encystation is due to the activation of hydrolytic enzymes within sedimentable compartments of the amoebae and is not the result of hydrolases being released from these compartments. It seems likely that agents which are capable of promoting encystation may do so by inducing activation of lysosomal enzymes.
\end{abstract}

\section{INTRODUCTION}

When starved completely of carbon and nitrogen sources and supplied with magnesium chloride the amoebae of Hartmannella castellanii encyst (Griffiths \& Hughes, I968, I969). The initiation of encystation is marked by large decreases in dry weight and protein which apparently provide the energy and precursors for the subsequent syntheses of cyst-specific components of which cellulose is the most prominent. The importance of this degradative phase suggests that encystation is a process in which it would be reasonable to expect lysosomal activity to play a significant role and there is now some evidence for the participation of autolysosomes in cyst-formation in Acanthamoeba sp. (Bowers \& Korn, 1969) and in another amoeba, Mayorella palestinensis (Lasman, 1967). As encystation can now be investigated under reasonably controlled experimental conditions it would seem to present a suitable system for the study of the control of lysosomal activity in developmental processes. 


\section{METHODS}

The organism used in this investigation was Hartmannella castellanii (NEFF strain). The amoebae were grown axenically in $4 \%$ mycological peptone (Oxoid) and encystation was induced by replacing the growth medium by $0.05 \mathrm{M}-\mathrm{MgCl}_{2}$ (Griffiths \& Hughes, 1968, 1969).

Cell-free extracts were prepared as follows. Amoebae were collected by centrifuging suspensions at $500 \mathrm{~g}$ for 3 to $5 \mathrm{~min}$., then the pellet was washed once with $50 \mathrm{mM}-\mathrm{MgCl}_{2}$ at laboratory temperature. In most experiments the washed amoebae were resuspended in $0.6 \mathrm{M}$-sucrose and gently disrupted in a glass hand-homogenizer fitted with a Teflon pestle (Thomas Ltd., Philadelphia) immersed in ice. The homogenate was centrifuged again at $500 \mathrm{~g}$ for $10 \mathrm{~min}$. to remove unbroken amoebae and the supernatant retained as the cell-free homogenate. Further fractionation of the homogenate was accomplished by centrifuging either at $800 \mathrm{~g}$ for $10 \mathrm{~min}$. followed by $20,000 \mathrm{~g}$ for 20 min., in a MSE 17 centrifuge, or at $20,000 \mathrm{~g}$ only. Pellets were resuspended in 5 to Io volumes of $0.6 \mathrm{M}$-sucrose buffered at $\mathrm{pH} 7.2$ with $20 \mathrm{mM}$-tris.

Acid phosphatase was assayed at $25^{\circ}$ with $p$-nitrophenylphosphate (Sigma Chemical Co.) as the substrate. The reaction mixture consisted of $0.2 \mathrm{ml}$. $100 \mathrm{mM}$ acetate buffer $(\mathrm{pH} 4.0$ ), $0.2 \mathrm{ml} .25 \mathrm{~mm}$-sucrose and $0.1 \mathrm{ml}$. of the enzyme preparation (2 to $30 \mu \mathrm{g}$ protein). The reaction was stopped after 5 to $10 \mathrm{~min}$. by the addition of $4 \mathrm{ml} .0 .5 \mathrm{M}$ $\mathrm{NaOH}$. The amount of $p$-nitrophenol released was measured at $400 \mathrm{~nm}$. on a Unicam SP600 spectrophotometer. Total phosphatase activities were measured on extracts which had been frozen and thawed; free phosphatase was measured on fresh, unfrozen extracts.

Protein was measured by the methods of Lowry, Rosebrough, Farr \& Randall (I95I) and Warburg \& Christian (Layne, I957). Amoebae were counted in a FuchsRosenthal haemocytometer (Griffiths \& Hughes, 1969).

\section{RESULTS}

The $p$-nitrophenylphosphatase of Hartmannella has a $\mathrm{pH}$ optimum of $4^{\circ} 0$. When assayed in freshly prepared extracts the phosphatase activity was much lower than in extracts which had been refrigerated overnight or frozen and thawed. This latency could also be released in the fresh extracts by incubating with Triton $\times 100$ or carbon tetrachloride (Table I). It was sufficient to freeze and thaw only once to release the maximum activity and for this reason measurements of total activity were always performed on frozen-thawed preparations.

Inclusion of sucrose in the media used to prepare cell-free homogenates of Hartmannella increased the sedimentability of acid phosphatase (Table 2). The use of sucrose concentrations up to $0.6 \mathrm{M}$ also brought about a decrease in the total measurable activity in association with the increase in sedimentability. Extracts prepared in $0.9 \mathrm{M}$-sucrose were $95 \%$ more active than those in $0.6 \mathrm{M}$-sucrose.

As expected, the sedimentable acid phosphatase also exhibited a greater degree of latency than the apparently soluble form of the enzyme. Freezing and thawing of the sedimentable fraction produced increases of 60 to $80 \%$ in the phosphatase activity compared with Io to $20 \%$ in the soluble fraction. The sedimentability of the acid phosphatase was characteristic of amoebae at all stages of growth (Table 3). Midlog phase amoebae which had been induced to encyst also showed a high proportion of 
sedimentable phosphatase after $6 \mathrm{hr}$ encystation (which corresponds to the mid-point of the hydrolytic phase of encystation (Griffiths \& Hughes, 1969)). In one encystation experiment the amoebae inexplicably lysed after $5 \mathrm{hr}$ incubation. It may be significant that in this culture only $28 \%$ of the recovered phosphatase activity was sedimentable.

Table I. Latency of acid phosphatase of H. castellanii

$\begin{array}{lc}\text { Treatment } & \begin{array}{r}\text { Increase in } \\ \text { activity }(\%)\end{array} \\ \text { Triton } \times \text { I00 } & 50 \\ \text { Refrigeration }\left(4^{\circ}, 24 \mathrm{hr}\right) & 60 \\ \text { Freezing and thawing } & 80 \\ \text { Carbon tetrachloride (10 } \mu \mathrm{l} .) & 40\end{array}$

Cell-free homogenates were prepared in $0.6 \mathrm{M}$-sucrose. Triton $\times 100$ and carbon tetrachloride were each added to the assay mixture. To relieve latency by freezing and thawing it was sufficient to freeze once $\left(\mathrm{I} 2 \mathrm{hr}\right.$ at $\left.-25^{\circ}\right)$ and thaw at laboratory temperature.

Table 2. Sedimentability of $H$. castellanii acid phosphatase at various sucrose concentrations

$\begin{array}{cccc}\begin{array}{c}\text { Sucrose concentration } \\ \text { in homogenate }\end{array} & \begin{array}{c}\text { Total activity } \\ (\mu \text { M- } p \text {-nitrophenol })\end{array} & \begin{array}{c}\text { Sedimented } \\ (\%)\end{array} & \begin{array}{c}\text { Recovery } \\ (\%)\end{array} \\ 0 & 90 & 15 & 60 \\ 0.3 \mathrm{M} & 94 & 38 & 70 \\ 0.6 \mathrm{M} & 83 & 79 & 86 \\ 0.9 \mathrm{M} & 162 & 58 & 70\end{array}$

Cell-free homogenates were prepared in media containing the indicated sucrose concentrations from the same culture of log-phase amoebae. All media were buffered at $\mathrm{pH} 7 \cdot 2$ with 20 mM-tris. Sedimentability was determined after centrifuging homogenates at $20,000 \mathrm{~g}$ for $20 \mathrm{~min}$. and resuspending the pellets in a medium containing sucrose at a concentration corresponding to that used during cell breakage. The percentage recovery of phosphatase activity following fractionation is also indicated.

Table 3. Sedimentability of acid phosphatase during growth and encystation

\begin{tabular}{|c|c|c|c|c|}
\hline & \multicolumn{4}{|c|}{$\begin{array}{c}\text { Per cent of total activity } \\
\text { of homogenate }\end{array}$} \\
\hline & \multicolumn{3}{|c|}{ Hours growth } & \multirow{2}{*}{$\begin{array}{c}\text { Hours } \\
\text { encystation } \\
6\end{array}$} \\
\hline & 24 & 48 & 72 & \\
\hline Sedimentable & 79 & 96 & I 28 & 86 \\
\hline Soluble & 10 & 23 & 30 & 17 \\
\hline Recovery (\%) & 89 & II 9 & 158 & 103 \\
\hline
\end{tabular}

Cell-free homogenates were prepared in $0.6 \mathrm{M}$-sucrose. Sedimentability was determined after centrifuging at $20,000 \mathrm{~g}$ for $20 \mathrm{~min}$.

Table 4 shows the activities of acid phosphatase in homogenates of Hartmannella during the degradative phase of encystation. Although the specific activity of acid phosphatase increased by $34 \%$ in the first $3 \mathrm{hr}$ of encystation the phosphatase activity per cell decreased. Some of the apparent increase in specific activity may be due not to an increase in the amount of enzyme but to the not insignificant proteolysis which occurs at this stage of encystation and which proceeds at an initial rate (during the first Io hr) of 4 to $5 \% / \mathrm{hr}$. The enzyme activities were measured in frozen-thawed 
extracts and therefore represent the total measurable phosphatase in the encysting amoebae. Table 3 shows the percentage of the total activity which was measurable in fresh homogenates and in fractions of amoebae after various periods of incubation in the encystation medium; this was the 'free' phosphatase activity. There were large increases in the free activities of the homogenates during the initial $5 \mathrm{hr}$ of encystation which were followed by a slight decrease between 5 and $8 \mathrm{hr}$. A similar pattern was found to occur in the phosphatases of the $800 \mathrm{~g}$ pellet and the $20,000 \mathrm{~g}$ supernatant. Free phosphatase activity in the $20,000 \mathrm{~g}$ pellet remained essentially at the same level throughout the hydrolytic phase of encystation.

Table 4. Total activities of acid phosphatase during the hydrolytic phase of encystation

$\begin{array}{lcc}\overbrace{\begin{array}{c}\text { Per mg. } \\ \text { protein } / \text { min. }\end{array}}^{\mu \mathrm{M}-p \text {-nitrophenol }} & \text { Per cell } / \mathrm{min} . \\ \text { O hr encystation } & 139 & 500 \\ \text { I hr encystation } & \text { I43 } & 400 \\ 3 \text { hr encystation } & \text { I86 } & 300 \\ 5 \text { hr encystation } & 140 & 120\end{array}$

Phosphatase activities were measured on frozen-thawed cell-free homogenates prepared in $0.6 \mathrm{M}$ sucrose. Samples were taken from the same culture.

Table 5. Free acid phosphatase activity in encysting $H$. castellanii

\begin{tabular}{lrrr} 
& \multicolumn{4}{c}{ Hours encystation } \\
Homogenate & 27 & 61 & 54 \\
$800 g \times$ I0 min. pellet & 16 & 50 & 33 \\
$20,000 g \times 20$ min. pellet & 42 & 50 & 50 \\
$20,000 g \times 20$ min. supernatant & 62 & 92 & 77
\end{tabular}

Free activities, which were measured on fresh preparations, are expressed as a percentage of the total activities which were obtained with the same extracts after freezing and thawing.

The encystation response of Hartmannella has been found to be sensitive to a number of carbon and nitrogen sources when these are included in the replacement medium. Addition of glutamic acid to an encysting culture completely blocks encystment and brings about the eventual death of the amoebae. When glucose is included in the encystation medium however, there is a significant enhancement of cellulose synthesis and there is also a sparing effect on the dry weight lost by the encysting amoebae. (Griffiths \& Hughes, I969). In an experiment devised to determine the effect of glucose and glutamate on the behaviour of acid phosphatase the amoebae were incubated for $15 \mathrm{hr}$ in the presence of these substrates. One per cent mycological peptone was used as a control as at this concentration neither growth nor encystation occur. The highest activity of phosphatase was found in amoebae which had been incubated in the normal encystation medium (Table 6). The activity in the cells incubated with glucose was only slightly higher than in those incubated in the peptone control. The highest sedimentable activities were found in those amoebae which eventually encysted.

When cell-free homogenates of Hartmannella were incubated with $\mathrm{MgCl}_{2}$, glucose and glutamate, all in $0.6 \mathrm{M}$-sucrose (Table 7 ), it was found that both glutamate and 
glucose depressed the measurable free activity whereas $\mathrm{MgCl}_{2}$ had an enhancing effect on the release of the phosphatase latency. Curiously, in view of their quite opposite effects on the encystation of whole amoebae, both $\mathrm{MgCl}_{2}$ and glutamate induced a release of acid phosphatase into the non-sedimentable fraction of the homogenate. In these experiments there was some spontaneous activation of the enzyme as the free activity in the control at the start of the incubation period was only $30 \%$ with $20 \%$ of the activity in the soluble phase.

Table 6. Acid phosphatase activity in amoebae following incubation with inhibitors and promoters of encystation

\begin{tabular}{|c|c|c|c|c|}
\hline & & $\begin{array}{l}\mu \mathrm{M}-p-\text { nitro- } \\
\text { phenol/cell }\end{array}$ & $\begin{array}{l}\text { Sediment } \\
(\%)\end{array}$ & $\begin{array}{l}\text { Soluble } \\
(\%)\end{array}$ \\
\hline No encystation & $\begin{array}{l}\text { I } \% \text { w/v Mycological peptone } \\
50 \mathrm{~mm} \text {-glutamate + } 50 \mathrm{mM}-\mathrm{MgCl}_{2}\end{array}$ & $\begin{array}{l}425 \\
122\end{array}$ & $\begin{array}{l}49 \\
54\end{array}$ & $\begin{array}{l}44 \\
39\end{array}$ \\
\hline Encystation & $\begin{array}{l}250 \mathrm{mM}-\mathrm{glucose}+50 \mathrm{mM}-\mathrm{MgCl}_{2} \\
50 \mathrm{mM}-\mathrm{MgCl}_{2}\end{array}$ & $\begin{array}{l}475 \\
595\end{array}$ & $\begin{array}{l}65 \\
68\end{array}$ & $\begin{array}{l}36 \\
27\end{array}$ \\
\hline
\end{tabular}

Amoebae were incubated for $15 \mathrm{hr}$ in media containing the substrates shown above. After harvesting cell-free homogenates were prepared in $0.6 \mathrm{M}$-sucrose. Sedimentability was determined after centrifuging homogenates at $20,000 \mathrm{~g}$ for $20 \mathrm{~min}$.

Table 7. Activation of acid phosphatase in homogenates of $H$. castellanii

\begin{tabular}{lrcc} 
& \multicolumn{3}{c}{ Per cent of total activity } \\
\cline { 2 - 4 } & Free & Sedimentable & Soluble \\
Control (initial) & 30 & 70 & 20 \\
Control (2 hr incubation) & 74 & 64 & 27 \\
$50 \mathrm{mM}-\mathrm{MgCl}_{2}$ & 87 & 24 & 94 \\
$50 \mathrm{mM}$ glutamate & 48 & 14 & 100 \\
$50 \mathrm{mM}$ glucose & 48 & 68 & 29
\end{tabular}

Amoebae were homogenized in $0.6 \mathrm{M}$-sucrose and the cell-free homogenate was incubated as shown at $30^{\circ}$. Free activities were measured on fresh extracts and total activities on frozen-thawed preparations.

\section{DISCUSSION}

The acid $\mathrm{pH}$ optimum, latency and sedimentability of the non-specific phosphatase of Hartmannella castellanii is strong evidence in favour of its lysosomal location. There were no spectacular increases in acid phosphatase levels in encysting Hartmannella as has been reported for the biochemically similar phenomenon of slime-mould sporulation (Gezelius, I966). It is quite clear though, that the mere measurement of total enzyme activities in eucaryotic organisms is of limited value in studies such as these when the enzyme in question may not have free access to its substrate in vivo. In the case of the Hartmannella phosphatase, for example, although there was no large increase in the level of this enzyme during encystation there were significant increases in its free activity. Furthermore, these increases did not occur in all sub-cellular fractions. How far these observations are representative of the in vivo situation can only be determined by further investigation and is now receiving attention. But the dry weight loss and extensive protein degradation which is known to occur in encysting amoebae (Griffiths \& Hughes, 1969) is, at least, circumstantial evidence in favour of such changes in the activities of the hydrolases. 
The persistent sedimentability of acid phosphatase in encystation is in contrast to the behaviour of this enzyme in starved Euglena (Bertini, Brandes \& Buetow, I965) and in the development of the chick urino-genital system (Scheib-Pfleger \& Wattiaux, 1962) in which hydrolytic activity is brought about by the release of the lysosomal enzymes into the soluble fraction of the cells. The highest levels of soluble acid phosphatase in Hartmannella were found in amoebae which had been prevented from encysting by the presence of glutamate or low concentrations of peptone and in the culture which had lysed. It seems likely, therefore, that the release of hydrolases from membrane-bound locales in the amoeba is inconsistent with encystation. This is understandable for certain enzymes or structures of the amoeba are required for the provision of energy and for syntheses in the differentiating cell and these must be protected from indiscriminate destruction by lysosomal enzymes released into the 'cytoplasm'.

Shibko, Pangborn \& Tappel (1965) have shown that the activation of rat-kidney lysosomal enzymes takes place in two stages. Initially there is an increase of the free activities of the hydrolases without loss of sedimentability. The second stage involves an almost complete release of the enzymes into the soluble phase. In the case of the Hartmannella phosphatase only activation by magnesium involved the latter. This observation is relevant to our understanding of the role of magnesium in promoting encystation and possibly to the activation of lysosomes in other cells, for Sawant, Desai \& Tappel (I694) have reported the activation of lysosomal aryl-sulphatase by magnesium ions in rat liver. In Hartmannella although the levels of acid phosphatase were higher in the amoebae which had been incubated with $\mathrm{MgCl}_{2}$ alone, most of this activity was still sedimentable. In view of this finding, and the indication that high levels of soluble acid phosphatase are inconsistent with encystation, the role of magnesium in encystation may still be interpreted as an inhibitor of the leakage of macromolecules which is known to occur in non-growing Hartmannella (Griffiths \& Hughes, 1968). Alternatively, the inhibition of acid phosphatase activation by glucose may also occur in vivo and antagonise the activating effect of magnesium chloride. There is a large accumulation of hexoses in encysting amoebae (Griffiths \& Hughes, 1968) which coincides with the phase of hydrolytic activity. The inhibitory effect shown by glucose is consistent with its probable role as a precursor for cellulose synthesis during encystation and with the observation that there is a substantial reduction in dry weight loss by amoebae induced to encyst in the presence of exogenous glucose (Griffiths \& Hughes, I969).

The presence of glutamate in the encystation medium depresses the phosphatase levels of the cells and also inhibits phosphatase activation in homogenates suggesting that glutamate may inhibit encystation by acting at the level of the lysosomes.

A.J.G. is the holder of a Medical Reseach Council Junior Research Fellowship and S.M.B. a Science Research Council Studentship.

\section{REFERENCES}

Bertini, F., Brandes, D. \& Buetow, D. E. (1965). Increased acid hydrolase activity during carbon starvation in Euglena gracilis. Biochem. biophys. Acta 107, 17 I.

Bowers, B. \& KorN, E. D. (1969). The fine structure of Acanthamoeba castellanii (Neff strain). II. Encystment. J. Cell Biol. 4r, 786.

Gezelius, K. (1966). Acid phosphatase in Dictyostelium discoideum. Physiologia Pl. 19, 946. 
Griffiths, A. J. \& Hughes, D. E. (I968). Starvation and encystment of a soil amoeba Hartmannella castellanii. J. Protozool. $\mathbf{5}, 673$.

Griffiths, A. J. \& Hughes, D. E. (1969) The physiology of encystment of Hartmannella castellanii. J. Protozool. 16, 93.

LaSman, M. (1967). Observations on acid phosphatase in Mayorella palestinensis. J. Cell. Physiol. 69, I5I.

Lowry, O. H., Rosebrough, N. J., FARR, A. L. \& Randall, R. J. (I95I). Protein measurement with the folin phenol reagent. J. biol. Chem. 193, 265.

LAYNE, E. (1957). Spectrophotometric and turbidometric methods for measuring proteins. Meth. Enzym. 3, 447.

Sawant, P. L., Desai, I. D. \& TAPPel, A. L. (1964). Factors affecting the lysosomal membrane and availability of enzymes. Archs Biochem. Biophys. 105, 247.

Scheib-Pfleger, D. \& Wattiaux, R. (I962). Etude des hydrolases acides des canaux de Müller de l'embryon de Poulet. I. Activités totales et solubles des canaux d'embryons de 8 à Io jours d'incubation. Devl. Biol. 5, 205.

Shibko, S., Pangborn, J. \& TAPpel, A. L. (1965). Studies on the release of lysosomal enzymes from kidney lysosomes. J. Cell Biol. 25, 479. 